Peter G. Duncan MD FRCPC, Marsha M. Cohen M SC MD MH SC FRCPC

\title{
Postoperative compli- cations: factors of significance to anaesthetic practice
}

In an attempt to define what factors are important to the development of postandesthetic complications, the data from a nine-year prospective study of anaesthetic practice in a large tertiary care institution were evaluated. A model of araesthetic morbidity dependent upon factors of (I) patient illness, (2) surgical practice. (3) unaesthetic lechnique and plyssician experience, and (4) duration of anaesthesia was developed. Postoperative anaesthetic morbidity was defined as any anaesthetic-related compliction which, in the opinion of the follow-up nurse, was associated with prolonged hospilalization or documented compromise of the patient.

Using a multiple logistic regression, ASA physical satus was a risk factor for postoperative complications (odds ratio $=1.95$ ) but the number of preoperative conditions and age were not. The rype of surgical procedure, classificd by site or by degree of irauna, did not infuence postanaesthetic comptication rates. The duration of anaestheric exposure was an important determinant of risk (odds ratio $=2.53$ ), with complications increasing with the length of anaesthetic sime. As tofactors under cotrol of the anaesthetist thase patients experiencing operating room complications (odds ratio $=3.36$ ) or those receiving pure spinat (odds ratio $=5.53$ ) or narcoric techniques (odds ratio $=2.14$ ) had higher risks of postoperative complications. Finally. it would appear that the greater the experience of the anaesthetist the less the risk of postoperative problents (odds ratio $=0.52$ ).

\section{Key words}

COMPLICATIONS: postoperative; STATISUICS: complications, anaesthesia; records: anaesthesia.

From the Departments of Anaesthesia and Pediatrics and the Department of Social and Preventive Medicine, Facutty of Medicine, University of Manitoba, Winnipeg. Manitoba. Address correspondence to: Dr. Peter Duncan. Department of Anaesthesia, University of Saskatchewan, University Hospi tal, Saskatoon, Saskatchewan, S7N OXO.

This research was supported by grants from the St. Boniface Hospital Research Foundation and a National Health Research Development Program postdoctoral fellowship to Dr. Cohen.

Presented in part at the 1986 meeting of the International Anesthesia Research Society, Las Vegas, NV
The practice of anaesthesia has changed significantly in recent years, with concommitant reductions in anaesthetic-related mortality. A recent review of studies of anaesthetic death rates suggests current mortality rate to be approximately $1: 10,000$ administered anaesthetics. ' While this low incidence appears to be acceptable, extrapolation to the number of anaesthetics given yearly suggests approximately 2000 patients will die annually due to anaesthetic complications in the U.S.A. alone. ${ }^{2}$ Clearly, factors relating to anaesthetic mortality need continued study on both a local and national basis.

Quality assurance of the discipline demands that the more frequent problem, andesthetic-related morbidity, be similarly studied. Unfortunately, there are few studies of nonfatal complications in the modem iiterature. Most reccnt articles ${ }^{3}$ are confined to consideration of those instances where medical liability occurred, and hence cannot give information as to the incidence of complications or the factors surrounding the problem. A recent study of morbidity related to anaesthesia practice in France ${ }^{4}$ was enlightening, but plagued by incomplete data collection.

Utilizing a previously described ${ }^{5}$ anaesthetic follow-up system, we recently reported the results of a nine-year survey of nonfatal anaesthetic complications in a large teaching hospital. ${ }^{6}$ That study suggested at least $17.5 \mathrm{per}$ cent of patients experienced some anaesthetic complication, with 0.45 per cent of patients suffering significant morbidity from the anaesthetic exposure. The present paper examines further the latter, the non-fatal postoperative complications attributed to anaesthesia, and analyzes factors associated with their occurrence.

Methods:

The anaesthetic follow-up program used to generate the database has been described earlier. ${ }^{5,6}$ In brief, for every adult patient anaesthetised at the Health Sciences Centre (obstetrical cases excluded) a record was made by the anaesthetist of the ASA classification of the patient's physical status, preoperative risk factors by organ system, and surgical procedure by site. The record contained 
information as to the anaesthetic technique used, drugs administered, monitors employed, complications encountered, and duration of the anaesthetic exposure. Recovery room complications were recorded on the same form by the recovery room nurse.

Most patients were seen the day following surgery and/or had their charts reviewed by a nurse specifically trained to rccognize anaesthetic complications; the same individual performed the task throughout the study pcriod. Using definitions developed for each complication, the presence or absence of anaesthetic-related complications was documented. The criteria for diagnosis varied for each complication sought, but remained constant over the years. Major complications considered herein were defined as those associated with documented morbidity or prolonged hospitalization, in contrast to other complications classified as merely discomfort or inconvenience. Before entry into the computerized data file, a final review was done by the responsible anaesthetist and the anaesthetic nurse to ensure accuracy and completeness.

Both as a validity check and to add additional demographic information about the patients, the anaesthesia database was successfully computer-linked to that of Manitoba's universal health insurance plan. This insurance plan with no premiums, hospital user limitations or deductibles thus accurately records all hospital utilization by residents of the province. The successful linkage between the two databases ensured that all anaesthetic encounters at this hospital were included in the study.

In the period of study (1975-1983) a total of 112,721 anaesthetics were administered. Fifty-five per cent of the cases $(62,999)$ were seen postoperatively by the anaesthetic nurse; those not seen were either day-surgery or short-stay patients discharged before review and assumed not to have sustained any postoperative complications. A complete description of the ASA physical status rating of the patients, the anaesthetic and surgical services rendered, and the complications which occurred has been published earlier. ${ }^{6}$ The present report elaborates on those cases demonstrating major postanaesthetic complications found upon review by the nurse.

In an effort to delineate which preoperative medical conditions were associated with anaesthetic complications, we determined the rate of intraoperative, recovery room, or postoperative complications, in patients with or without a given preoperative illness. On the anaesthetic form quantitation of the severity of either the preoperative illness or the complication identified was not possible; only its presence or absence was recorded. The duration of the anaesthetic exposure was similarly examined in relationship to the frequency of postoperative complications. Finally, the data were analysed as to whether patients with intraoperative complications subsequently suffered major postoperative morbidity.

The data are expressd as risk ratios; for example, the rate of complications in those having a preoperative illness is divided by the rate of complications in those not having the same preoperative illness. Statistical significance of these risk ratios was calculated according to the method of Kahn.?

A two-stage process was used to determine potential risk factors for postoperative complications. First, univariate analysis was used to test the significance of cach independent variable with regard to the dependent variable of interest using the chi-square test. Independent variables included: (a) variables related to the anaesthetist (the number of procedures performed per year, the number of years as an anaesthetist at the sludy hospital), (b) the anaesthetic procedure (number of drugs used, inhalation, narcotic or spinal anaesthesia, number of monitors used), (c) the surgical procedure (major versus minor surgery, length of anaesthesia), and (d) patient characteistics (age, sex, number of preoperative medical conditions and ASA physical status score).

Second, forward stepwise multiple logistic regression was then used to separate the relative roles of the risk factors to anaesthetic morbidity. In this statistical model each variable is examined while controlling for all other possible confounding variables. For example, the relative odds of having a postoperative complication can be determined for patients rated ASA III-V as compared to patients rated ASA I-II who are having the same surgery, are of the same age and sex, and are having the same anaesthetic by an anaesthetist of the same experience. Since various categorization of the variables did not affect the final outcome, dummy variables were used to facilitate interpretation. Odds ratios and 95 per cent confidence limits were then determined and statistical significance was accepted at the $\mathrm{p} \leq 0.05$ level.

\section{Results}

The relationship of preexisting medical illness to operative anaesthetic complications is presented in Table I. It can be seen that generally the rate of complications is higher for those patients with preopcrative conditions as compared to those without preexisting illness. For example, the rate of intraoperative complications was 2.1 times higher in patients with a previous myocardial infarction (MI) as compared to patients who did not have a myocardial infarction $(\mathrm{p}<0.05$ ). Complications also tended to $\propto$ cur in the same system as was involved in the preopcrative illness. Using the same example, patients with a previous MI were much more likely to have intraoperative complications such as arrhythmias (risk ratio $=2.3$ ), hypotension (risk ratio $=3.1$ ), or byperten- 
TABLE I Preoperative risk factors vs operative or postoperative complications (risk ratios) ${ }^{*}$

\begin{tabular}{|c|c|c|c|c|c|c|c|}
\hline \multirow[b]{2}{*}{ Complicarion } & \multicolumn{7}{|c|}{ Preoperalive conditiont } \\
\hline & $M t$ & Other CVS & Respiratory & Renal & Obesiny & Drivg & Metabolic \\
\hline \multicolumn{8}{|l|}{ Inuraoperative } \\
\hline Any & $2.1 \ddagger$ & $2.1 \ddagger$ & $1.7 \ddagger$ & $1,4 \ddagger$ & $1.3+$ & $1.7 \ddagger$ & $1.5 \ddagger$ \\
\hline Arrythmia & $2.3 \ddagger$ & $2.0 \ddagger$ & $1.4 \ddagger$ & $1.2 \ddagger$ & 1.2 & $1.4 \ddagger$ & 1.27 \\
\hline Hypotension & $3.1 \div$ & $3.5 \ddagger$ & 2.4 & $2.4 \ddagger$ & $1,4 \ddagger$ & $2.1 \neq$ & $2.3 \div$ \\
\hline Hypertension & $3.4 \ddagger$ & $4.8 t$ & 2.17 & $1.5 \ddagger$ & $1.7 \ddagger$ & $2.3 \ddagger$ & $1.7 \ddagger$ \\
\hline Respiratory & 1.0 & 0.9 & $2.9 \ddagger$ & 0.7 & $1.8 \neq$ & 1.1 & 0.9 \\
\hline Drug & 1.2 & 0.7 & 1.2 & 0.6 & 0.6 & 1.0 & $1.9 \ddagger$ \\
\hline Cardiac arrest & $2.7 t$ & $3.5 \ddagger$ & 1.8 & $10.4 \ddagger$ & $1,9 \ddagger$ & 1.2 & $3.0 \ddagger$ \\
\hline \multicolumn{8}{|l|}{ Recovery room } \\
\hline Any & $2.0 \div$ & $2.1 \ddagger$ & 1.4 & $1.9 \ddagger$ & $1.4 \ddagger$ & $1.7 \ddagger$ & $1.6 \mp$ \\
\hline Amythmia & $48 \mp$ & $4.6 \ddagger$ & $21 t$ & 2.17 & $1.8 \pm$ & $2.5 \$$ & $2.1 \ddagger$ \\
\hline Hypotension & $1.4 \neq$ & $1.3 \ddagger$ & 0.9 & $1.0 \ddagger$ & $1.3 \div$ & 1.37 & $1.3 \neq$ \\
\hline Hypertension & $2.4 \ddagger$ & $3.8 \ddagger$ & $1.4 \ddagger$ & $2.5 \ddagger$ & $1.9 \neq$ & $2.3 \ddagger$ & 1.2 \\
\hline Respiratory & $1, \overline{3}$ & $2.0 \ddagger$ & $2.4 !$ & $2.4 \ddagger$ & 2.17 & $2.3 \ddagger$ & $1.8 \neq$ \\
\hline Drug & 1.3 & 1.8 & 1.0 & $4.5 \ddagger$ & 1.8 & 1.8 & 2.0 \\
\hline Cardiac arres: & $3.2 \ddagger$ & $3.5 \ddagger$ & 1.4 & $3.5 \ddagger$ & 0.4 & 1.6 & 1.7 \\
\hline \multicolumn{8}{|l|}{ Posloperative } \\
\hline Any & 1.1 & $1.2 \ddagger$ & $0.8 t$ & 0.9 & $1.3 \%$ & 1.0 & 1.0 \\
\hline Major & $2.7 \ddagger$ & $2.8 \ddagger$ & $1.5 \$$ & $2.3 \$$ & 1.1 & 1.67 & $2.3 \ddagger$ \\
\hline Myocardial infarction & $10.3 \neq$ & $5.5 \ddagger$ & $3.1 \ddagger$ & $3.0 \%$ & 0.6 & $2.7 \ddagger$ & $2.6 \ddagger$ \\
\hline Other cardiovascular & $4.6 \div$ & 3.6 & $1.7 \ddagger$ & 1.4 & 1.4 & $2.5 \ddagger$ & $1.8 \ddagger$ \\
\hline Respiratory & 0.7 & 1.0 & 9.97 & - & $2.4 \ddagger$ & 1.6 & $2.8 \ddagger$ \\
\hline
\end{tabular}

"Ratio of complication rate in patients with a given condition divided by the complicarion rate in patients wizhour the condition †Missing data indicates a rate of zero in one group. $\ddagger_{\mathrm{p}} \leq 0.05$.

sion (risk ratio $=3.4$ ). They were 2.0 times as likely to have a recovery room complication and 4.8 times more likely to have an arrhythmia in the recovery room. They were nearly three times more likely to have a major postoperative complication, especially one referrable to the cardiovascular system (risk ratio $=4.6$ ) or a postoperative myocardial infarction (risk ratio $=10.3$ ).

Similarly, patients with preoperative respiratory conditions were more likely to have an intraoperative (risk ratio $=1.7$ ), recovery room (risk ratio $=1.4$ ) or postoperative major complication (risk ratio $=1.5$ ). They were also at risk for higher rates of cardiovascular complications, but to a lesser degree than for respiratory related conditions. Patients with other preoperative illness including renal, drug and metabolic disease also had elevated risks for any intraoperative and recovery room complication. Renal patients were particularly at high risk for cardiovascular complications such as intraoperative cardiac arrest (risk ratio $=10.4$ ) or postoperative myocardial infarction (risk ratio $=3.0$ ). Patients deemed obese by the anaesthetists demonstrated a slightly higher rate of complications, especially respiratory related, during the intraoperative period (risk ratio $=1.8$ ), recovery room (risk ratio $=2.1$ ) and postoperative (risk ratio $=2.4$ ). It should be noted that many patients had more than one preoperative medical condition which may explain the increased risk of intraoperative, recovery room and postoperative complications which were not specific to the organ system identified preoperatively as a problem.

There was a striking increase in anaesthetic complications with an increased anaesthetic time (Table II),

TABLE II Anaesthetic time vs anaesthetic complications

\begin{tabular}{|c|c|c|c|}
\hline \multirow{2}{*}{$\begin{array}{l}\text { Length of } \\
\text { anaesshesia }\end{array}$} & \multirow{2}{*}{$\begin{array}{l}\text { Intraoperative } \\
\text { complications } \\
\text { (\%o patients) }\end{array}$} & \multirow{2}{*}{$\begin{array}{l}\text { Recovery room } \\
\text { complicutions }\end{array}$} & \multirow{2}{*}{$\begin{array}{l}\text { Major } \\
\text { postoperative } \\
\text { complication } \\
\text { (\$o patients) }\end{array}$} \\
\hline & & & \\
\hline \multicolumn{4}{|l|}{$0-29$ minutes } \\
\hline$N=9,356$ & 2.28 & 1.64 & 0.13 \\
\hline \multicolumn{4}{|l|}{ 30-59 minutes } \\
\hline$N=33,737$ & 6.15 & 3.01 & 0.10 \\
\hline \multicolumn{4}{|l|}{$60-119$ minutes } \\
\hline$N=19,952$ & 8.92 & 3.53 & 0.17 \\
\hline \multicolumn{4}{|l|}{$120+$ minutes } \\
\hline$N=49,676$ & 13.48 & 7.17 & 0.39 \\
\hline
\end{tabular}


including those which occurred intraoperatively, in the recovery room, and detected during postoperative followup of patients. The relationship was most marked with regard to major postoperative complications, where procedures with more than 120 minutes of anaesthetic time were associated with a doubling of the complication rate.

In order to determine if the occurrence of an intraoperative complication is a risk factor for subsequent morbidity, the rate of subsequent complications was determined. The results are presented in Table III. Overall, there is a significant increase (risk ratio $=3.5$ ) in patient morbidity in the wake of intraoperative problems. The effect is of most concern for relatively healthy patients (ASA I and II) undergoing emergency surgery (risk ratio $=6.5$ ).

While preoperative medical conditions and length of anaesthesia were related to the occurrence of operativerelated complications, several other factor's such as age, ASA status, type of surgery and expcrience of the anacsthetist complicate these associations. In order to assess the relative contribution of these variables to postoperative outcomes, multiple logistic regression analysis was used. Results are presented in Table IV.

After controlling for other factors, lengthy anaesthesia was still statistically associated with the risk of having a postoperative major complication, with procedurcs of more than 120 minutes, being 2.53 times more likely to have a complication. It is of interest that patient factors such as age and number of preoperative conditions did not have a bearing on postoperative morbidity after controlling for physical status. Similarly major surgery did not prove to be a significant factor. The occurrence of an

TABLE III Per cent patients with postoperative major complications among those with and without intraoperative complications

\begin{tabular}{llll}
\hline & $\begin{array}{l}\text { Rate of } \\
\text { postoperative } \\
\text { complications in } \\
\text { patients with } \\
\text { intraoperative } \\
\text { complications (\%) }\end{array}$ & $\begin{array}{l}\text { Rate of } \\
\text { postoperative } \\
\text { complications in } \\
\text { patients wishout } \\
\text { intraoperative } \\
\text { complications (\%) }\end{array}$ & Risk \\
ASAtio
\end{tabular}

*Due to small sample size, postoperat ive complications in these patients were not detectable.

$\dagger_{\mathrm{p}} \leq 0.05$.
TABEE IV Risk factors for major postoperative complications (logistic regression results)

\begin{tabular}{|c|c|c|}
\hline & $\begin{array}{l}\text { Relarive } \\
\text { culds }\end{array}$ & $\begin{array}{l}\text { (95\% confidence } \\
\text { limi(s) }\end{array}$ \\
\hline \multicolumn{3}{|l|}{ Ancesthetic lime (mimutes) } \\
\hline $120+160$ & 2.53 & $(1.55,4.14)^{*}$ \\
\hline $60-120 / 60$ & 1.67 & $(0.93,3.00)$ \\
\hline \multicolumn{3}{|l|}{ Pacient factors } \\
\hline ASA III-VIASA I-II & 1.95 & $(1.34,2.85)^{\star}$ \\
\hline Sex males/females & 1.60 & $(1.14,2.22) \dagger$ \\
\hline Age $>50 /<50$ & 1.22 & $(0.75,1.95)$ \\
\hline Number of preoperative conditions & 0.99 & $(0.72,1.38)$ \\
\hline \multicolumn{3}{|l|}{ Surgical factors } \\
\hline Major/minor procedures & 0.89 & $(0.60,1.25)$ \\
\hline \multicolumn{3}{|l|}{ Ancesthetic factors } \\
\hline Spinal/inhalation & 5.53 & $(3.00,10.15) \ddagger$ \\
\hline Narcotic/inhalation & 2.14 & $(1.49,3.08) \mp$ \\
\hline Number of drugs & 0.93 & $(0.60,1.46)$ \\
\hline Number of monitors & 1.15 & $(0.88,1.30)$ \\
\hline \multicolumn{3}{|l|}{ Previous intraoperative } \\
\hline Complications yes/no & 3.36 & $(2.39,4.70) \ddagger$ \\
\hline \multicolumn{3}{|l|}{$\begin{array}{l}\text { Experience of the anaesthetist } \\
(>600+\operatorname{cascs} / \mathrm{yr} \text { for } 8+\text { years })\end{array}$} \\
\hline (<350 cases/yr for 8 years) & 0.52 & $(0.38,0.70) \ddagger$ \\
\hline \multicolumn{3}{|l|}{ Year of surgical procedure } \\
\hline $1978-80 / 1975-77$ & 0.58 & $(0.40,2.50) \dagger$ \\
\hline $1981-83 / 1975-77$ & 0.70 & $(0.47,1.03)$ \\
\hline
\end{tabular}

intraoperative problem or the use of spinal or pure narcotic techniques were associated with postanaesthetic morbidity. In addition, experience of the anaesthetist became a factor in the occurrence of postanaesthetic complications in that more experienced anaesthetists had fewer complications than those with lesser experience. Patients whose surgical procedures were performed in recent years had fewer complications after controlling for differences in patient case mix over time (risk ratio = 0.58).

\section{Discussion}

Postanaesthetic morbidity has been defined for the purpose of this paper as any complication attributed to the anaestheic experience which resulted in prolonged hospitalization or patient compromise. While our previous report ${ }^{6}$ had noted up to ten per cent of patients will experience some complication after a procedure, the rate of major complications was much less at 0.45 per cent. 
The present paper concentrates on this latter group, for, from a patient's point of view, the problems constitute more than an inconvenience and are a potential source of dissatisfaction. An understanding of the factors related to such morbidity is necessary before preventive measures can be taken.

The causes of anaesthetic and surgical complications are many, making definitive statements difficult and generalizations among institutions tenuous. For example, the incidence of mortality following surgery in 1224 hospitals in the U.S.A. varied 2.2 times between the best 16 institutions and the worst 16 , the only significant difference being the expenditures per patient for surgical care ${ }^{8}$ This same "institutional differences" study showed the hospital organization was more important than the surgeon in predicting adverse outcomes, the only significant variable in the surgeon's control being the number of residencies completed. Clearly, if valid predictions of risk for a given surgical procedure are to be given to an inquiring patient, extrapolations from other centres with different medical personnel must be made with caution.

The present study represents a large data base generated in a prospective fashion and uses defined cirteria for postoperative complications as recognized by a constant observer over the nine years of study. While potential for subjectivity in assessment is obviously a possibility (e.g.: in ASA ranking) the large number of physicians recording the data would minimize any single divergent opinion. Similarly reporting bias in complication rates is quite possible, but again would be minimized by the large number of cases, the large number of participating anaesthestists, and the independent review of each chart before data entry by the follow-up nurse. Nevertheless, while such bias is acknowledged as potential it would probably be in the direction of reduced reporting of complications rather than increased.

To no great surprise, the initial examination of the data found that patients with preexisting illness were more likely to suffer anaesthetic complications. These tended to be organ-specific, but having any preexisting problem tended to place a patient at higher risk. However, such a conclusion must be tempered with the recognition that a given preoperative problem may dictate a closer perioperative observation (and hence complication detection) that does not occur without preoperative identification of a problem. Alternatively, the presence of preoperative risk factors may dissuade the surgeon and anaesthetist from usual practice, limiting operative services to more critial or more major procedures with prolonged anaesthetic time as a result. Thus a cause-and-effect relationship between preoperative illness and anaesthetic complications remains to be definitively demonstrated.

To control statistically for such confounding variables the logistic regression method was employed. An unexpected finding was that a significant factor bearing upon late complications was the duration of anaesthesia. Variables relating to the anaesthestist (generally centred about the experience and pattern of practice) were also found to be associated with postoperative morbidity in that patients of experienced anaesthetists were less likely to have problems than those cared for by inexperienced physicians. Variables related to the anaesthetic (spinal and pure narcotic techniques) were also associated with more complications after controlling for patient characteristics and complexity of surgery.

Patient factors such as physical status but not age or number of previous illness were important in the rate of postoperative problems. Variables pertaining to the specific anaesthetic drugs and monitoring seemed less important, confirming a clinical impression that it is not the drugs but who gives them that is critical. Finally, the surgical procedure performed (major/minor) bore little influence on postanaesthetic morbidity, except by resulting in prolonged duration of anaesthesia. It must be acknowledged that this might reflect the nature of the complications sought in this particular anaesthetic study as opposed to the entire issue of operative morbidity. However, the failure of the operative procedure to influence the rate of postanaesthetic complications suggests the two disciplines are not as intertwined as previously supposed. While intraoperative complications vary with the clinical situation as to their nature and severity, if promptly recognized and managed, they need not necessarily cause lasting morbidity. Indeed, the essence of modem monitoring is prompt detection of such change in patient status. In fact, it was reassuring to find that the risk of major postoperative complications was decreased in recent years.

The relationship of anaesthetic duration to anaesthetic complications is difficult to explain on a physiologic or pharmacologic basis. Most physiological consequences of anaesthesia occur during induction, with little change thereafter in the presence of a stable anaesthetic state. For example, the reduction in lung volume predisposing to respiratory complications occurs on induction, with little change thereafter. ${ }^{2}$ The cardiovascular effect of volatile agents correlates with anaesthetic depth, but actually improves over time with halothane. ${ }^{10}$ While cellular anaesthetic effects may be dose and time related ${ }^{11}$ the complications in question bear little relationship to demonstrated cellular or metabolic phenomena due to anaesthetic drugs or their metabolic products.

Support for the significance of anaestheric time as an inportant variable comes from at least one study examining the reinfarction rate in patients with previous myocardial infarctions. ${ }^{12}$ In that work the only significant 
operative factors bearing on that complication were demonstrated hypotension and anaesthetic time. However, there was no control for the extent of surgical trauma, suggesting that the prolonged time under anaesthesia may have been necessary because of more major surgery and hence greater physiologic trespass. In the logistic regression analysis described here major surgery (defined as intracranial, intrathoracic, intraabdominal and major vacular procedures) was controlled and therefore not a significant factor.

An alternative explanation for the influence of time is to attribute the relationship of complications to the time at risk for misadventure. Indeed, when considered in conjunction with the importance of the anaesthetist's profile of experience to postoperative major complications it is a very plausible explanation. Cooper ${ }^{13}$ pointed out the high ( 83 per cent) incidence of human error in the analysis of anaesthetic misadventure in the operating room. Similarly, Utting ${ }^{3}$ has described the important role of physician error in anaesthetic-related liability for postoperative complications. The usefulness of an experienced anaesthetist in minimizing anaesthetic complications is certainly born out by the negative assucialion of complications to experience demonstrated in this study,

While the data analysed here are from only one institution and one group of anaesthetic specialists, it does contain information important to all anaesthetic practice. We have found that despite sicker patients presenting more frequently for more major procedures, modern anaesthetic techniques are capable of safely handling the intraoperative course. While preexisting disease and aggressive surgery may dictate more invasive monitoring or alternative anaesthetic methods, the complications that occur can be recognized and handled to minimize subsequent morbidity. This advanced knowledge and technology has contributed greatly to our ability to service the population. Unfortunately, until we louk closely at the provider of the service and the factors bearing upon his capabilities we may not be able to eradicate morbidity from modern anaesthetic practice.

\section{Acknowledgements}

The authors are indebted to the members of the Department of Anesthesia, Health Sciences Centre, Winnipeg, especially D.B. Craig, W.D.B. Pope, C. Wolkenstein and $M$. Burnham.

\section{References}

1 Davies IM. Strunin L. Anesthesia in 1984: how safe is it? Can Med Assoc J 1984: 131: 437-41.

2 Cooper JB. Towards prevention of anesthetic mishaps. In: Anaesthetic Clinics 1984: 22: 167-83.

3 Utting $J E$, Gray $T C$, Shelley $F C$. Human misadventure in anaesthesia. Can Anaesth Soc J 1979; 26: 472-8.

4 Hatton $F$, Tiret $L$, Vourch $G$, Desmonss JC. Otteni JC. Scherporeel $P$. Morbidity and mortality associated with anesthesia - French survey, preliminary results. In: Mortality in anesthesia. MD Vickers, JN Lunn (eds). SpringerVerlag, Berlin 1982: 26-38.

5 Burnham M, Craig DB. A post-anaesthesia follow-up program. Can Anaesth Soe J 1980; 27: 164-8

6 Cohen MM, Duncan PG, Pope WDB, Wolkenstein C. A survey of 112,000 anaesthetics at one teaching hospital (1975-83). Can Anaesth Soc J 1986; 33: 22-31.

7 Kahn, HA. An Introduction to Epidemiologic Methods. Oxford University Press: New York 1983.

8 Flood AB, Hospital orgarization and outcomes of care I $n$; Health care delivery in anesthesia. RA Hirsh, WH Forrest, FK Orkin, H. Wollman (eds). George F. Stickley Co., Philadelphia 1980: 105-18.

9 Weenig CS, Pietak S, Hickey RF, Fairley HB. Relationship of preoperative closing volume to functional residual capacity and alveolar-arterial oxygen difference during anesthesia with controlled ventilation. Aresthesiology $1974 ; 41: 3-8$.

10 Eger EI, Smith NT, Cullen DN, Cullen BF, Gregory GA. A comparison of the cardiovascular effects of halothanc, fluoroxene, ether and cyclopropane in man. Anesthesiology $1971 ; 34: 25-41$.

11 O'Suliwan H, Jennings, F, Ward K, McCann S, Scou JM. Weir DG. Human bone manow biochenical function and megaloblastic hematopoieses after nitrous oxide anesthesia, Anesthesiology 1981; 55: 645-9.

12 Steem PA. Tinker JH, Tarhan S. Myocardial reinfarction after anesthesia and surgery. JAMA 1978; 239: 2566-70.

13 Cooper JB, Newblower RS, Long CD, MCPeek B. Preventable anesthesia mishaps - a study of human factors. Aresthesiology 1978; 49: 399-408. 


\section{Résumé}

Dans un effort tentant de définir les facteurs importants dans le développement des complications postanesthésiques, tes données de neuf ans de pratique anesthésique dans une grande instiution de soins tertiaires ont été évaluées par une étude prospecive. Un modèle de morbidité anesthésique en fonction des facteurs tels que () la maladie du patient, 2) la technique chirurgicale, 3) la technique anesthésique et l'expérience du médecin, et 4) la durée de l'anesthésie, a été développé. Lu morbidité anesthésique postopératoire a été définie comme éant toute complication reliée à l'anesthếsie, qui d' après l' infirmière s'occupant du suivi du patient, était assaciëe avec une huspialisation prolongée ou un état crifique documenté du patient.

Utilisant la méthode de régression logistique multiple, l'état physique du paient tel qu'évalué par les normes de l'ASA était un facteur de risque de complications postopératoires (odds ratio $=1.95$ ). Cependant le nombre des conditions préopératoires ainsi que l'âge n'étaient pas des facteurs de risque pouvant prédire des complications postopératoires. Le tope de procédure chirurgicale classifié par site ou par degré de trauma, n'a pas infuencé le taux de complication postanesthêsique. La durée de l'anesthésie était un déterminant important du risque (odds ratio $=2.53$ ), la fréquence des complications augmentans avec l'augmentotion de la duré de l'anesthésie. Quant aux facteurs sous contrôle direct de l'anesthésiste nous notons que les patients exposés au préalable aux complications en salle d'opération (odds ratio $=3.36$ ) et ceux ayant reçu une anesthésie rachidienne pure lodds ratio $=5.53$ ) ou des techniques narcotiques (adds ratio $=2.14$ ) ont présenté un plus grand risque de camplications postopératoires. Finalememt il semble que plus grande est l'expérience de l'anesthésiste moindre est le risque de complications postopératoires lodds ratio $=0.521$. 